\title{
THE LAST OPTION FOR PAIN MANAGEMENT - COMBINED CRYO-TECHNIQUE IN BLIND EYES WITH ABSOLUTE GLAUCOMA
}

\author{
Marin Marinov, Ralitsa Neykova, Dimitar Grupchev, Dobrin Boyadzhiev, \\ Christina Grupcheva
}

Department of Ophthalmology and Visual Sciences, Faculty of Medicine, Medical University of Varna

\begin{abstract}
AIM: To evaluate the efficiency and safety of simultaneous, combined cryotherapy and alcohol injection in cases of secondary neovascular glaucoma with absolute vision loss and intolerable pain syndrome. Ocular pain due to glaucoma can be complex and difficult to treat. Therapy consists of topical and systemic pressure lowering agents, anti-inflammatory drugs, analgesics, surgical procedures - cyclocryotherapy, retrobulbar alcohol injection, enucleation or evisceration.
\end{abstract}

MATERIALS AND METHODS: We present 35 patients diagnosed with absolute glaucoma and treated with a combined technique - cyclocryotherapy and retrobulbar alcochol $96 \% 1 \mathrm{ml}$ injection. Verbal Analog Score (VAS) was used to evaluate the pain.

RESULTS: All of the patients (100\%) were pain-free 12 months after the procedure. No significant longterm complications were observed.

CONCLUSION: This case study highlights that cyclocryotherapy combined with retrobulbar alcohol can play a significant role in the management of pain in patients with absolute glaucoma.

Keywords: pain, retrobulbar alcohol, cyclocryotherapy, absolute glaucoma, neovascular glaucoma

\section{INTRODUCTION}

Absolute glaucoma is an end-stage disease, characterized with non-functional or absent vision, high intraocular pressure, and usually disturbing pain syndrome. In the clinical practice this is the well-known syndrome of a painful blind eye. Despite the medical therapy or the surgical procedures (laser therapy or trabeculectomy), eyes with absolute glaucoma maintain high, uncontrolled intraocular pres-

\footnotetext{
Address for correspondence:

Marin Marinov

15 Doyran $S t$

9002 Varna

Bulgaria

e-mail:pensiqtabg@abv.bg
}

Received: June 26, 2017

Accepted: June 30, 2017 sure. It is usually higher than $30 \mathrm{mmHg}$ and presents with a normal aqueous production of the ciliary body, but a reduced outflow through the chamber angle due to proliferation or fibrovascular tissue growth (1). Patients complain of significant, disturbing pain, which can adversely affect the quality of life. Once lost, vision cannot be regained, so the focus should be on maintaining vision in the fellow eye, psychological and other support, helping the patient to keep the affected eye comfortable, reasonable cosmetic appearance, etc. (2). If conservative measures do not result in improved comfort for the patient, then pain can be relieved with retrobulbar injection of chlorpromazine (3) or absolute alcohol (4). Another option is cyclocryotherapy $(5,6)$. If this is not effective, or there is a cosmetic concern, then evisceration or enucleation can be considered with subsequent restauration with ocular prosthesis. The 
Marin Marinov, Ralitsa Neykova, Dimitar Grupchev et al.

management of ocular pain is complex and requires a multidisciplinary approach involving specialties such as anaesthesiology, ophthalmology, neurology and at times a specialized psychologist (7). Retrobulbar alcohol injection is a viable option for pain relief in patients who have cosmetically acceptable eyes as well as those who are either unwilling or unfit for more extensive surgery and subsequent management (8). Also, cyclocryotherapy provides good intraocular pressure control and good pain control. Combined techniques could be used with even higher success ratio and good patient outcome.

\section{AIM}

The aim of this study was to determine the role of cyclocryotherapy combined with retrobulbar alcohol $96 \% 1 \mathrm{ml}$ injection in the management of severe ocular pain in patients with absolute glaucoma.

\section{MATERIALS AND METHODS}

This retrospective, multicenter study was based on the medical documentation of three different hospitals. It was conducted at the Ophthalmic Department of Multi-profile Hospital for Active Treatment, Shumen over a period of 9 years $(2000$ - 2009) - 20 patients, Eye Clinic "D-r Taskov", Targovishte over a period of 8 years $(2009$ - 2017) - 5 patients, Specialized Eye Hospital, Varna - 10 patients. All of the patients were hospitalized. Patients under 18 years of age and complicated cases with an active orbital disease or a neurological deficit were excluded from the study.

A total of 35 patients were included. The procedure was performed in the operating room under proper asepsis. After instilling anaesthetic (proxymetacaine hydrochloride $0.5 \%$ ) drops in the inferior fornix, $2 \%$ lidocaine was injected subcutaneously in the inferotemporal quadrant, providing injection site analgesia. A 25-gauge retrobulbar needle was then passed into the retrobulbar space and a mixture of $2 \mathrm{ml} 2 \%$ lidocaine and $2 \mathrm{ml} 0.75 \%$ bupivicaine (Marcaine) was injected. After an interval of five minutes, the anaesthetic effect was clinically visible. Then twelve equidistant cryo-applications were applied over the ciliary body region, starting $2 \mathrm{~mm}$ behind the limbus over 360 degrees with a size of $2.5 \mathrm{~mm}$. For all cases retinal detachment cryo-probe was utilized. Each application was a 60 s freezing cycle to - 80 degree Celsius. After the last application, a 25 -gauge injection in the retrobulbar space added a mixture of $1 \mathrm{ml} 2 \%$ lidocaine and $1 \mathrm{ml} 96 \%$ alcohol. Antibacterial and non-steroidal anti-inflammatory drops were prescribed.

The severity of pain was recorded using verbal analogue score (VAS) ranging from 0 to 10 , with 10 being the highest. The patients' VAS was recorded before and after the procedure. Three more records were made - on the first week, on the first month and on the first year after the surgery. At each follow-up the patients were assessed for development of complications.

\section{RESULTS}

The mean age was 74 years ( \pm 10 years range), 18 male $(51.43 \%)$ and 17 female $(48.57 \%)$ patients. The right eye was involved in 16 patients (45.71\%) and the left - in 19 patients (54.29\%).

Patients' mean VAS score before, after the surgery and on the three follow-up visits is shown in Table 1. Before the surgery, the mean VAS was 9.16 ranging from 10 points to 7 points. After the surgery, the mean VAS decreased to 2.88 with measure-

Table 1. Pain assesment scores before and after treatment with combined cryo-alcohol treatment of eyes without useful vision

\begin{tabular}{|c|c|c|c|c|c|}
\hline Patients & $\begin{array}{c}\text { Mean VAS before } \\
\text { surgery }\end{array}$ & $\begin{array}{c}\text { Mean VAS after } \\
\text { surgery }\end{array}$ & $\begin{array}{l}\text { Mean VAS on the } \\
\text { first week }\end{array}$ & $\begin{array}{l}\text { Mean VAS on the } \\
\text { first month }\end{array}$ & $\begin{array}{l}\text { Mean VAS on the } \\
\text { first year }\end{array}$ \\
\hline $\begin{array}{l}\text { Total } \\
35\end{array}$ & $\begin{array}{c}9.16 \\
\text { (from } 10 \text { to } 7 \text { ) }\end{array}$ & $\begin{array}{c}2.88 \\
\text { (from } 8 \text { to } 1 \text { ) }\end{array}$ & $\begin{array}{c}1.16 \\
(\text { from } 5 \text { to } 0)\end{array}$ & $\begin{array}{c}0.16 \\
(\text { from } 2 \text { to } 0)\end{array}$ & $\begin{array}{c}0.12 \\
(\text { from } 1 \text { to } 0)\end{array}$ \\
\hline $\begin{array}{l}\text { Male } \\
18\end{array}$ & $\begin{array}{c}9.50 \\
\text { (from } 10 \text { to } 7 \text { ) }\end{array}$ & $\begin{array}{c}3.35 \\
(\text { from } 8 \text { to } 1)\end{array}$ & $\begin{array}{c}1.20 \\
(\text { from } 5 \text { to } 0)\end{array}$ & $\begin{array}{c}0.17 \\
(\text { from } 2 \text { to } 0)\end{array}$ & $\begin{array}{c}0.12 \\
\text { (from } 1 \text { to } 0)\end{array}$ \\
\hline $\begin{array}{l}\text { Female } \\
17\end{array}$ & $\begin{array}{c}8.82 \\
\text { (from } 10 \text { to } 7 \text { ) }\end{array}$ & $\begin{array}{c}2.41 \\
\text { (from } 7 \text { to } 1 \text { ) }\end{array}$ & $\begin{array}{c}1.12 \\
(\text { from } 5 \text { to } 0)\end{array}$ & $\begin{array}{c}0.15 \\
\text { (from } 2 \text { to } 0)\end{array}$ & $\begin{array}{c}0.12 \\
\text { (from } 1 \text { to } 0)\end{array}$ \\
\hline
\end{tabular}


ments from 8 points to 1 point. On the first week the mean VAS score was 1.16 with the highest measurement being 5 points and the lowest - 0 points. On the first month after the surgery, the mean VAS dropped to 0.16 ranging from 2 points to 0 points. One year after the surgery the mean VAS was 0.12 and all of the measurements were mainly 0 points and rarely 1 point.

All of the patients (100\%) were on topical treatment for two weeks after the injection. Five (20\%) required topical treatment for one month. All of the patients required mild lid edema and conjunctival chemosis which resolved within two weeks after surgery.

\section{DISCUSSION}

The management of patients with pain syndrome and blind eye presents several challenges to ophthalmologists (9). Both cyclocryotherapy and retrobulbar alcohol injection are simple and efficient methods to control pain. Alcohol and other neurolytic agents exert their effect by destroying the nerve fibers by coagulative necrosis $(4,7)$. The technique must be performed with accuracy, the alcohol must be injected in close proximity to the nerve fibers. A dampening of the nerve fiber conduction is achieved but it is possible for the pain to recur again with time.

Cyclocryotherapy leads to pain management, because of lowering the IOP. The technique is widely used and there are many studies but the results, however have been conflicting. A stable decrease in IOP have been reported in $80 \%-0 \%$ (10). Such variation in the results is probably due to individual differences in ciliary body anatomy and sensitivity of the eye tissues to low temperatures.

Zhonghua conducted a study of 37 eyes with non-neovascular and neovascular glaucoma treated with cyclocryotherapy and followed up for 3-67 months (11). Pain was controlled in $86.7 \%$ of the cases, which corresponds to the outcome of our study.

Benson presented a retrospective study to evaluate the efficacy and complication rate of cyclocryotherapy on 68 eyes (12). Of the painful eyes, $71 \%$ were rendered comfortable. The study stated that cyclocryotherapy affords good pain relief, without good pressure control, in various types of glaucoma. These results are very similar to the one from our study.

Further to those studies, Kim studied the longterm results from cyclocryotherapy in 20 eyes and concluded the method to be a reasonable treatment option for patients with refractory glaucoma, who experience ocular pain and headaches (13). Janicijevic conducted a study over 203 eyes - 152 patients in a period between 2005 and 2010 (14). Measurements of IOP were taken before and after cyclocryotherapy. The study concluded that cyclocryotherapy was a useful and accessible method for control of intensive pain in neovascular glaucoma. This corresponds to the conclusions in our study.

A mixture of short-acting local anesthetics such as lidocaine and marcaine were administered before the cyclocryotherapy not only to provide anesthetic effect that reduces intraoperative pain, but also to ensure correct placement of the needle in the retrobulbar space (15).

The success rate in pain relief after retrobulbar alcohol injection is also variable and ranges between $87 \%-20 \%$ in Medline indexed literature. A combined technique between cyclocryotherapy and retrobulbar alcohol injection provided rapid and lasting pain relief. Twenty-three patients were pain-free within 1 week and all 25 reached this state within one year after surgery. This is comparable to the results of other studies.

Cok et al. conducted a study of the effect of retrobulbar injection on 4 patients of absolute glaucoma (16). They reported a period of pain relief lasting up to one year, which matches the results of our study.

Kumar reported a case of adenoid cyst carcinoma of the maxillary sinus. The patient was suffering from severe intractable pain in the orbital region due to exposure and compression effect of the tumor (6). The pain was not controlled under a maximum dose of analgesics. Kumar used a single retrobulbar injection of alcohol. The patient was pain-free for a period of 6 months, prior to his death.

Akhtar conducted a study of 5 cases. The patients were with blind, painful eyes due to absolute glaucoma (17). Each patient received a single retrobulbar alcohol injection and VAS was recorded in similar manner to our study. Eighty percent of the patients were pain-free on the first week and 100\% all of the 5 patients were pain-free on the first year after the injection. These results correspond to the results in our study. 
Marin Marinov, Ralitsa Neykova, Dimitar Grupchev et al.

Birch observed the effect of retrobulbar phenol injection in painful eyes. Eighty percent of the patients included in the study were suffering from absolute glaucoma. They observed a mean pain-free period of 15 months after injection (18).

Another study was done by Maumenee to observe the effect of retrobulbar alcohol in 35 blind and 15 seeing painful eyes (19). He reported a painfree period of 1-3 months with no permanent longterm complications. These findings are comparable to those, observed in our study.

In a study Al-faran conducted, a variable period of pain relief ranging from 2 weeks to 2 years was found. Thirty-nine eyes were included in the study, 31 had pain due to end-stage glaucoma (20). The conclusion was that retrobulbar alcohol may be a useful alternative to enucleation or evisceration in the management of painful blind eyes.

The study identified several postoperative complications - anesthesia of the skin overlaying the cheek, lid and brow, conjunctival chemosis and lid edema. These were comparable to those seen in published literature (21). All these complications were temporary and resolved without any intervention within 2 weeks after surgery. Complications such as transient ptosis, proptosis and external ophthalmoplegia have been documented in Medline indexed literature, but were not observed in this study.

In our study we combined the cyclocryotherapy with retrobulbar injection of alcohol and demonstrate notable improvement of pain within reasonable post-operative treatment. Interestingly, we found a little more pain in males than in examined females, however the final result was equal. This method appear to be efficient, safe and suitable as last resort treatment for eyes without useful vision and significant pain syndrome. We recommend the aforementioned methodology and have proven that it can be used in differing surgical conditions with equal success.

\section{CONCLUSION}

The effect of a combined technique - cyclocryotherapy and retrobular alcohol injection was studied in the presented cases and it was found to be safe and effective. It is a last resort technique and might be used and repeated in cases with prominent pain syndrome.

\section{REFERENCES}

1. Lee WR, Absolute Glaucoma. Ophthalmic Hystopathology. London: Springer; 2002, p. 63-99.

2. Gessesse GW, Damji KF. Advanced Glaucoma: Management Pearls. Middle East Afr J Ophthalmol. 2013; 20(2):131-41. doi: 10.4103/0974-9233.110610

3. Chen TC, Ahn Yuen SJ, Sangalang MA, Fernando RE, Leuenberger EU. Retrobulbar chlorpromazine injections for the management of blind and seeing painful eyes. J Glaucoma. 2002;11(3):209-13.

4. Skorin L. Treatment of Blind and Seeing Painful Eye. [online] Jan 162004 Available from: www.optometry.co.uk

5. Bietti G. New Trends for the Relief of Glaucoma.JAMA. 1950;142(12):889-97. doi: 10.1001/ jama.1950.02910300027006

6. Sinha A, Rahman A. Cyclocryotherapy in absolute glaucoma. Indian J Ophthalmol. 1984;32(2):77-80.

7. Kumar CM, Dowd TC, Hawthorne M, Retrobulbar Alcohol Injection for Orbital Pain Relief Under Difficult Circumstances: A Case Report. Ann Acad Med Singapore. 2006; 35:260-5.

8. Shah-Dessai SD, Tyers AG, Manners RM. Painfull Blind Eye: Efficacy of Enucleation and Evisceration in Resolving Ocular Pain. Br J Ophthalmol. 2000; 84: 437-8. doi: 10.1136/bjo.84.4.437

9. Merbs SL. Management of blind painful eye. Ophthalmol Clin North Am. 2006; 19:287-92. doi: 10.1016/j.ohc.2006.02.010

10. Prost M. Anatomy of the Ciliary Body and Cyclocryotherapy.Ophthalmologica. 1984; 188:9-13. doi: 10.1159/000309338

11. Zhonghua Yan Ke Za Zhi. Cyclocryotherapy in the treatment of glaucoma.1990;26:98-101. PMID:2390906 (in Chinese)

12. Benson MT, Nelson ME. Cyclocryotherapy: a review of cases over a 10 -year period. Br J Ophthalmol. 1990;74:103-5.

13. Kim BS, Kim YJ, Seo SW, Yoo YM, Kim SJ. Longterm results from cyclocryotherapy applied to the 3 o'clock and 9 o'clock positions in blind refractory glaucoma patients. Korean J Ophthalmol. 2015;29:47-52.

14. Janicijevic-Petrovic MA, Sarenac T, Petrovic M, Vulovic D, Janicijevic K. Cyclocryotherapy in neovascular glaucoma treatment. Med Glas (Zenica). 2012;9:106-9. 
15. Webber SK, McGhee CN, McMenamin PG. Precautionary note on retrobulbar Alcohol injections. Br J Ophthalmol. 1995; 79(2):192-4.

16. Cok OU, Eker HE, Cantuerk S, Yaycioelu R, Ariboean A, Arslan G. Pain management in blind, painful eyes: clinical experience with retrobulbar alcohol injection in 4 cases. Agri. 2011; 23(1): 43-6. doi: 10.5505/agri.2011.99705

17. Akhtar N, Tayyab A, Kausar A, Jaffar S. Pain management with retrobulbar alcohol injection in absolute glaucoma. J Pak Med Assoc. 2015; 65(6):678-80.

18. Birch M, Strong N, Brittain P, Sandford-Smith J. Retrobulbar phenol injection in blind painful eyes. Ann Ophthalmol. 1993; 25(7):267-70.

19. Maumenee AE. Retrobulbar alcohol injections: relief in ocular pain in eyes with and without vision. Am J Ophthalmol. 1949;32(11):1502-8. doi: 10.1016/ S0002-9394(49)90370-0

20. Al-Faran MF, Al-Omar OM. Retrobulbar alcohol injection in blind painful eyes. Ann Ophthalmol. 1990; 22(12):460-2.

21. Olurin O, Osuntokun O. Complications of retrobulbar alcohol injections. Ann Ophthalmol. 1978;10(4):474-6. 